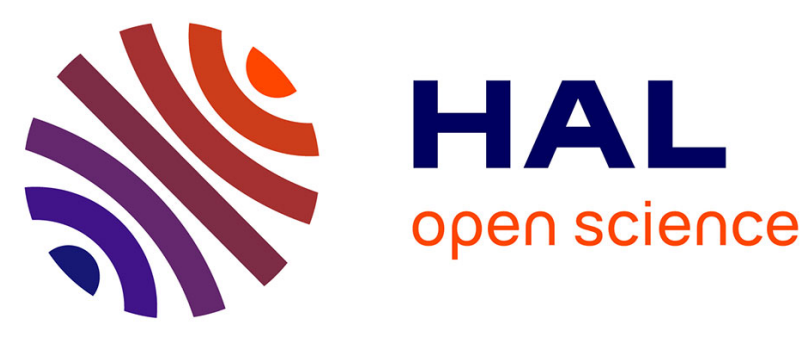

\title{
Design of the rapidly relocatable tagged neutron inspection system of the C-BORD project
}

\author{
Alix Sardet, Bertrand Perot, Cédric Carasco, Guillaume Sannié, Sandra \\ Moretto, Giancarlo Nebbia, Cristiano Fontana, Marek Moszynski, Pawel \\ Sibczynski, Krystian Grodzicki, et al.
}

\section{To cite this version:}

Alix Sardet, Bertrand Perot, Cédric Carasco, Guillaume Sannié, Sandra Moretto, et al.. Design of the rapidly relocatable tagged neutron inspection system of the C-BORD project. 2016 IEEE Nuclear Science Symposium, Medical Imaging Conference and Room-Temperature Semiconductor Detector Workshop (NSS/MIC/RTSD), Oct 2016, Strasbourg, France. pp.1-5. hal-01990337

\section{HAL Id: hal-01990337 https://hal.science/hal-01990337}

Submitted on 23 Jan 2019

HAL is a multi-disciplinary open access archive for the deposit and dissemination of scientific research documents, whether they are published or not. The documents may come from teaching and research institutions in France or abroad, or from public or private research centers.
L'archive ouverte pluridisciplinaire HAL, est destinée au dépôt et à la diffusion de documents scientifiques de niveau recherche, publiés ou non, émanant des établissements d'enseignement et de recherche français ou étrangers, des laboratoires publics ou privés. 


\title{
Design of the Rapidly Relocatable Tagged Neutron Inspection System of the C-BORD project
}

\author{
Alix Sardet, Bertrand Pérot, Cédric Carasco, Guillaume Sannié, Sandra Moretto, Giancarlo Nebbia, Cristiano \\ Fontana, Marek Moszyński, Pawel Sibczyński, Krystian Grodzicki, Lukasz Świderski, Alessandro Iovene, Carlo \\ Tintori
}

\begin{abstract}
Within the framework of the European $\mathbf{H 2 0 2 0}$ C-BORD project, aiming at improving container inspection technologies, a compact and "Rapidly Relocatable Tagged Neutron Inspection System", called RRTNIS, is being developed taking into account past EURITRACK experience with a portal TNIS, and the latest technologies in terms of associated particle neutron generator and data acquisition electronics. A dedicated shield surrounding the neutron generator has been designed with MCNP6 to limit the size of the restricted area and the count rate on gamma detectors, which are located very close to the generator. This new design with "reflection" detectors only, i.e. in backscattering position, is indeed more efficient to detect suspect items, like explosives or illicit drugs, in bottom regions of the container, compared to EURITRACK detectors which were mainly located above the container. It also allows designing a relocatable system for different inspection sites like seaports, borders, or other checkpoints. Dose and count rate calculations are presented to determine the restricted area and facilitate the design of the data acquisition electronics, respectively.
\end{abstract}

Index Terms - TNIS (tagged neutron inspection system), APT (associated particle technique), illicit materials, CBRNE (Chemical, Biological, Radiological, Nuclear, and Explosives) threats, Monte Carlo simulation

\section{INTRODUCTION}

Increase in worldwide trade is accompanied by an escalation in contraband, traffic of dangerous and illicit substances (drugs, explosives ...), illegal immigration, etc. Due to the diversity of these targets, a unique Non-Intrusive Inspection (NII) technology is not able to cope. In the scope of European H2020 projects dedicated to the development of "Technologies for inspections of large volume freight", the C-BORD (effective Container inspection at BORDer control

Manuscript received April 3, 2016. This work has received funding from the European Union's Horizon 2020 research and innovation programme under grant agreement No 653323. This text reflects only the author's views and the Commission is not liable for any use that may be made of the information contained therein.

A. Sardet, B. Pérot and C. Carasco are with CEA, DEN, Cadarache, Nuclear Measurement Laboratory, F-13108 Saint-Paul-lez-Durance, France (email: alix.sardet@cea.fr).

G. Sannié is with CEA, DRT, LIST, Saclay, F-91191 Gif-Sur-Yvette, France.

S. Moretto, G. Nebbia and C. Fontana are with Dipartimento di Fisica e Astronomia e INFN di Padova, via Marzolo, 8, I-35131 Padova, Italy.

M. Moszyński, P. Sibczyński, K. Grodzicki and L. Świderski are with the National Centre for Nuclear Research, A. Soltana 7, PL 05-400 OtwockSwierk, Poland.

A. Iovene and C. Tintori are with CAEN S.p.A, Via Vetraia, 11, I-55049 Viareggio, Italy. points) project proposes a toolbox of five NII technologies (radiation portal monitor, improved X-ray scanner, RRTNIS, photofission, and evaporation based detection) working in combination to ensure a cheaper, faster, and safer inspection of containerized freight. These integrated solutions will then be trialed on three custom sites, representative of end-user cases: Rotterdam and Gdańsk seaports, in The Netherlands and in Poland respectively, and mobile land-border checkpoints in Hungary.

This paper reports on improvements made to the C-BORD RRTNIS, with respect to the EURITRACK TNIS [1], [2], in terms of shielding and compactness.

\section{The TAgGed NeUtron InsPeCtion TECHNIQUE}

Using an associated particle generator, a $14 \mathrm{MeV}$ neutron beam is produced through the ${ }^{2} H+{ }^{3} H \rightarrow n+\alpha$ fusion reaction. As the alpha particle is emitted almost back-to-back with the neutron, its detection, with a position sensitive YAP detector, gives information on neutron direction. Gamma rays, resulting from the interaction of these neutrons with materials inside the cargo container, are detected using inorganic $\mathrm{NaI}(\mathrm{Tl})$ and $\mathrm{LaBr}_{3}(\mathrm{Ce})$ scintillators. The time difference between gamma and alpha detections, combined with neutron direction information, enables the selection of any elementary volume unit (voxel), which was deemed suspicious by a prior X-ray radiography of the cargo container. Material identification is performed through gamma-ray spectroscopy. The NaI gamma energy spectrum is unfolded using a database of elementary gamma signatures induced by tagged neutrons, previously determined during calibration acquisitions. For organic compounds, target identification is performed by determining the relative proportions of carbon, nitrogen, oxygen and comparing the obtained results with a reference material database. This principle is illustrated in Fig. 1.

An additional classification was also performed with the EURITRACK system between metallic, organic and ceramic goods. Furthermore, for C-BORD, it also planned to detect chemical warfare agents by recognizing their characteristic gamma rays. $\mathrm{LaBr}_{3}$ detectors will be used to identify specific low-energy $(<1 \mathrm{MeV})$ gamma rays, which are sign the presence of elements such as arsenic or bromine [3]. 


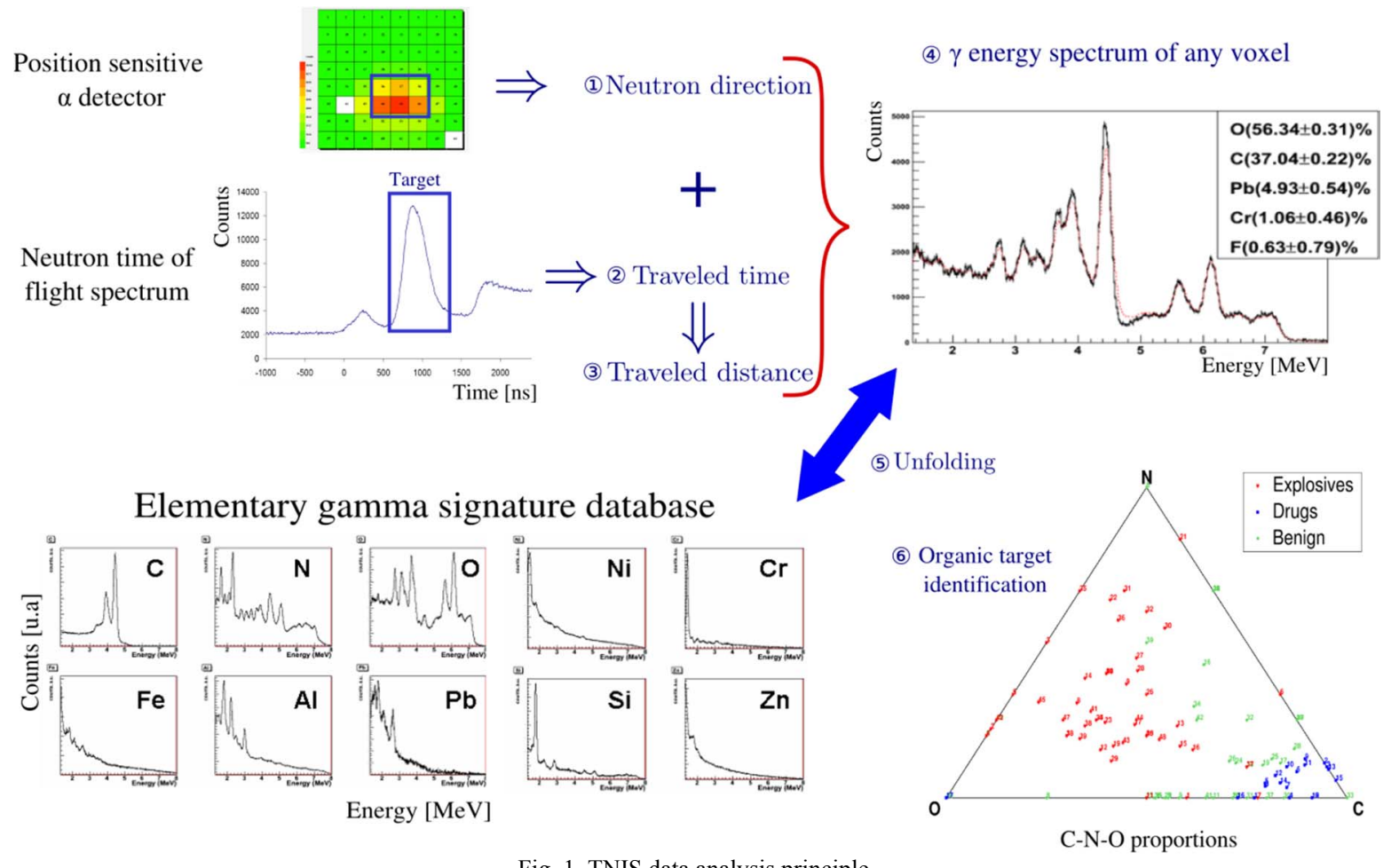

Fig. 1. TNIS data analysis principle.

\section{THE C-BORD RAPIDLY Relocatable TAGged NEUTRON INSPECTION SYSTEM}

\section{A. General design}

Unlike the TNIS used in the past EURITRACK project, the C-BORD system is developed with the constraint of being compact and rapidly relocatable. It is designed in such a way that the required exclusion area will be as small as reasonably achievable, while balancing radioprotection considerations with mechanical constraints. In addition, all detectors are placed in a backscattering position relatively to the tagged neutron beam, as opposed to above the inspected container in the EURITRACK portal. This new position is more efficient for the detection of threats located in the bottom part of the container [4]. Indeed, gamma rays are less attenuated by the cargo matrix before reaching the detectors. Another advantage of this position is that it makes feasible the placement of all elements of the RRTNIS (generator, detectors, batteries, etc.) on a single elevating platform. Therefore, the system no longer requires the construction of fixed portal facilities, which renders it relocatable, within about 48 hours, to different European custom sites.

A general view of the C-BORD RRTNIS is presented in Fig. 2. The top part pictures the system and its components, while the bottom part illustrates how it will be positioned relatively to the inspected container. On this last drawing, a $400 \times 600 \times 50 \mathrm{~cm}^{3}$ polyethylene beam-dump has also been added in order to stop the neutron beam transmitted beyond the container. The following paragraphs will discuss these elements in more details.

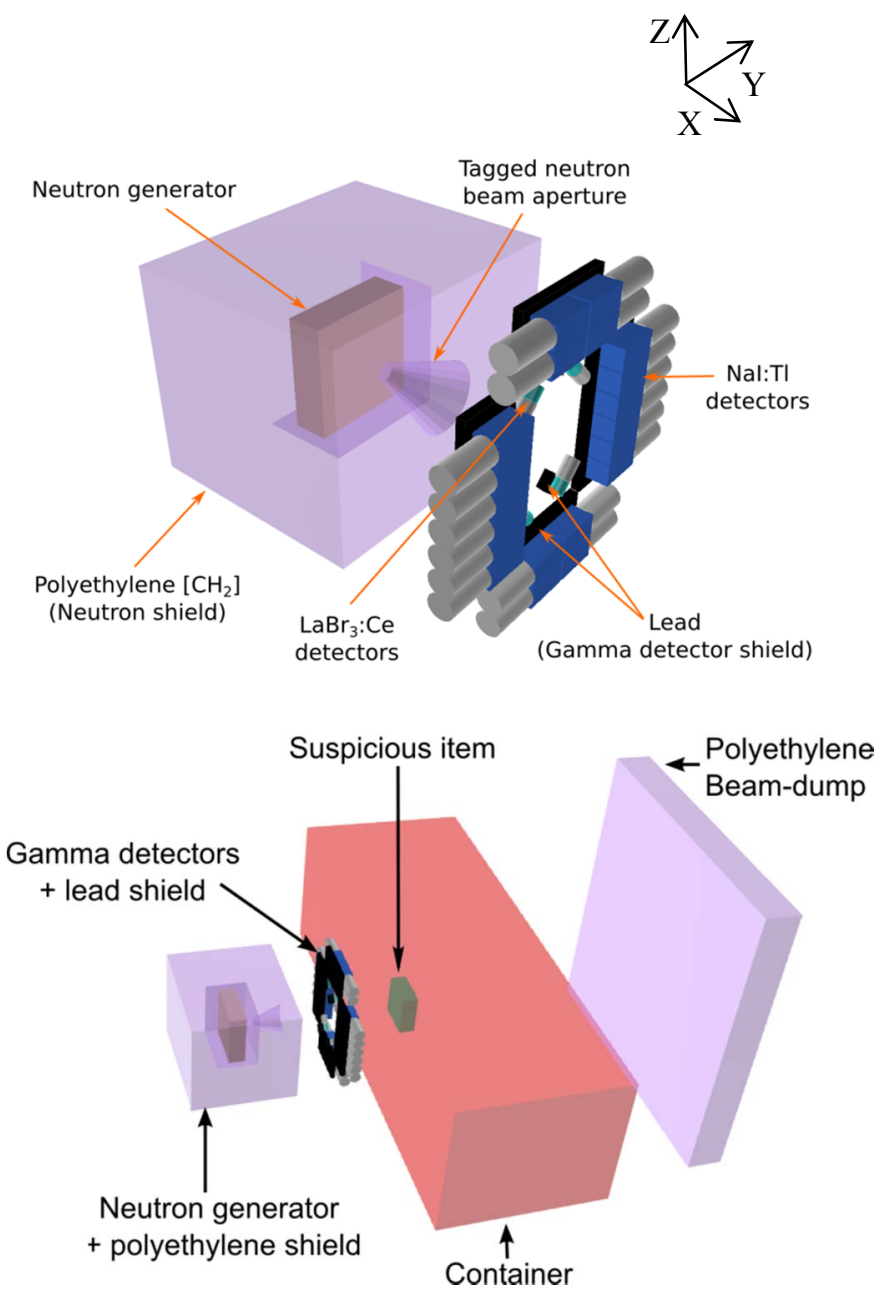

Fig. 2. General 3D view of the RRTNIS. 


\section{B. Neutron generator shield}

The neutron generator used during the EURITRACK project will be replaced by a brand new model, under development by SODERN, with a potentially 10 times higher neutron emission rate $\left(10^{8}\right.$ vs. $\left.10^{7} \mathrm{n} / \mathrm{s}\right)$.

According to specifications from the C-BORD project, just around the RRTNIS restricted area the radiological exposure of non-radiation workers must be smaller than $1 \mu \mathrm{Sv} / \mathrm{h}$ and $1 \mathrm{mSv} /$ year. To respect the $1 \mu \mathrm{Sv} / \mathrm{h}$ dose rate limit, without any shield, an exclusion area of $80 \mathrm{~m}$ in diameter would be needed. Since such a free terrain is not available, simulations have been performed, using the MCNP6 code, to design a shield reducing this area to the available terrain borders, while keeping the RRTNIS weight and geometrical dimensions as small as possible.

The shield is a parallelepiped made of polyethylene, chosen for its neutron stopping power and low density $\left(0.94 \mathrm{~g} . \mathrm{cm}^{-3}\right)$, with a conical excavation for the tagged neutron beam (see Fig. 2). For simulation purposes, the neutron generator was assimilated to a point-like $14 \mathrm{MeV}$ neutron source with an emission rate of $10^{8} \mathrm{n} / \mathrm{s}$. The floor was modelled by a $100 \mathrm{~cm}$ thick layer of 2.35 g.cm $\mathrm{cm}^{-3}$ concrete. Neutron and photon dose rate maps have been calculated using the mesh tally of MCNP6, convolved with flux-to-dose conversion factors from [5]. Calculations show that only the neutron dose rate is significant for the determination of the size of the exclusion area. Indeed, even without the polyethylene shield, the gamma dose rate is below $0.5 \mu \mathrm{Sv} / \mathrm{h}$ at a distance of $5 \mathrm{~m}$ from the neutron generator.

A series of parametric studies have been performed in order to optimize the neutron shield. Several materials, (e.g. 5\% borated polyethylene) have been considered but were not retained as they did not significantly decrease the dose rate (about $1 \%$ at $5 \mathrm{~m}$ ) and were rather costly (about 1.5 times more expensive [6], [7]).

Another relevant parameter is the lateral shield thicknesses, represented by $\mathrm{e}_{\mathrm{CH} 2}$ in Fig. 3, with the neutron beam directed along the $\mathrm{X}$-axis.
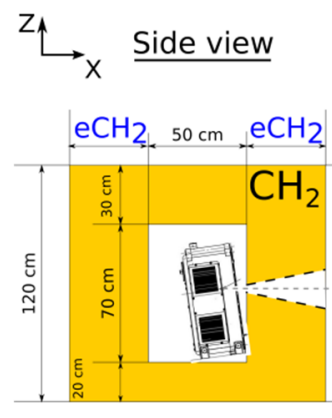
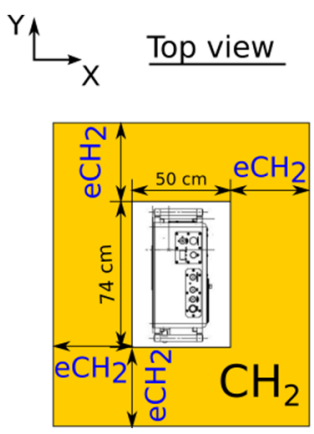

Fig. 3. Geometry of the neutron shield. The lateral thickness of the shield $\mathrm{eCH} 2$ is used as a variable parameter in the simulations.

This thickness has been varied between $35 \mathrm{~cm}$ and $50 \mathrm{~cm}$ by $5 \mathrm{~cm}$ steps. Table I presents, for each thickness, the associated volume, the total weight (shield + detectors) and the distance at which the $1 \mu \mathrm{Sv} / \mathrm{h}$ limit is reached.
TABLE I. SUMMARY OF SEVERAL SHIELD CONFIGURATIONS TESTED WITH MCNP6 CALCULATIONS. THE TOTAL WEIGHT CORRESPONDS TO THE APPROXIMATE WEIGHT ON THE MECHANICAL STRUCTURE $\left(\mathrm{CH}_{2}+\mathrm{LEAD}+\right.$ DETECTORS). THE LAST COLUMN PRESENTS THE DISTANCE AT WHICH THE DOSE RATE REACHES $1 \mu \mathrm{SV} / \mathrm{H}$. IT WAS CALCULATED ACCORDING TO THE 1/D 2 LAW.

\begin{tabular}{cccc}
$\begin{array}{c}\mathrm{CH}_{2} \\
\text { thickness } \\
(\mathrm{cm})\end{array}$ & $\begin{array}{c}\mathrm{CH}_{2} \\
\text { dimensions } \\
\left(\mathrm{cm}^{3}\right)\end{array}$ & $\begin{array}{c}\text { Total weight } \\
\text { (tons) }\end{array}$ & $\begin{array}{c}\text { Distance at } \\
\text { which } \\
1 \mu \mathrm{Sv} / \mathrm{h} \text { is } \\
\text { reached }(\mathrm{m})\end{array}$ \\
\hline 35 & $120 \times 144 \times 120$ & $\approx 3.0$ & 16.6 \\
40 & $130 \times 154 \times 120$ & $\approx 3.3$ & 14 \\
45 & $140 \times 164 \times 120$ & $\approx 3.6$ & 11.9 \\
50 & $150 \times 174 \times 120$ & $\approx 3.9$ & 10 \\
\hline
\end{tabular}

A $40 \mathrm{~cm}$ thick polyethylene shield around the generator was chosen as the best compromise between an efficient radiological protection, which allowed fitting the exclusion area in the borders of the available terrains, and a system as compact and light as possibly achievable. For such a shield design, the needed restricted area has a width of $\pm 15 \mathrm{~m}$ along the Y-axis. Its length depends on whether the polyethylene beam-dump, shown in Fig. 2, has been constructed or not. In the first case (see Fig. 4 (a)), a length of $\pm 20 \mathrm{~m}$ along the Xaxis (tagged neutron beam) is required. Without beam-dump (see Fig. 4(b)), the length is increased to $60 \mathrm{~m}$.
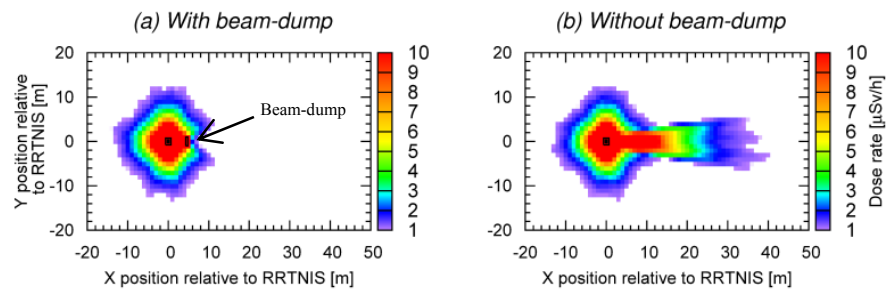

Fig. 4. Neutron dose rates at human height, with a $1 \mu \mathrm{Sv} / \mathrm{h}$ lower limit, calculated for a $40 \mathrm{~cm}$ thick polyethylene shield around the neutron generator with (a) and without (b) the $50 \mathrm{~cm}$ thick polyethylene beam-dump of Fig. 2.

A last set of simulations was performed in order to assess the effect of cargo materials on the neutron dose rate map. Indeed, some materials have a high neutron-reflecting power, which could change the neutron dose rate around the RRTNIS. Considering the high number of possible cargo, extensive simulations could not be performed. Therefore, only polyethylene $\left(0.94 \mathrm{~g} . \mathrm{cm}^{-3}\right)$, graphite $\left(1.6 \mathrm{~g} . \mathrm{cm}^{-3}\right)$, iron $(7.8$ g.cm $\left.{ }^{-3}\right)$ and water $\left(1 \mathrm{~g} . c m^{-3}\right)$ were considered. This study showed that the presence of cargo increases the dose rate behind the neutron generator. However, even for iron which has the highest neutron scattering cross-section, the previously defined restricted area remains valid.

\section{Gamma detectors}

During the EURITRACK project, twenty $\mathrm{NaI}(\mathrm{Tl})$ detectors were used to detect gamma rays with a $0.6-8 \mathrm{MeV}$ energy range [8], appropriate for the detection of illicit drugs and explosives. In order to extend the system detection capabilities to chemical threats, according to the study presented in [9], 
four $\mathrm{LaBr}_{3}(\mathrm{Ce})$ detectors were added to the system to allow the detection of lower energy radiations (down to approximatively $100 \mathrm{keV}$ ) with a sufficient resolution to separate these gamma rays.

As shown in the previous section, the polyethylene shield around the neutron generator efficiently stops $14 \mathrm{MeV}$ neutrons. However, neutron interactions in the polyethylene are the source of intense gamma emissions, and therefore of a background contribution on gamma detectors.

The expected energy spectra recorded by gamma detectors have been simulated using the pulse height (F8) tally of MCNP. Fig. 5 presents the results obtained on a NaI detector: the addition of polyethylene around the generator causes the apparition of two peaks at $2.223 \mathrm{MeV}$ and $4.439 \mathrm{MeV}$, resulting respectively from neutron capture by hydrogen nuclei and from neutron inelastic scattering on carbon nuclei of the polyethylene shield.

As this background noise would be prejudicial to a proper identification of the inspected target, a $5 \mathrm{~cm}$ thick lead plate was inserted between polyethylene and gamma detectors (see Fig. 2). The blue dotted spectrum obtained in this final configuration shows a significant reduction of the $2.223 \mathrm{MeV}$ and $4.439 \mathrm{MeV}$ peaks, and of the whole background spectrum by a factor 4 approximately.

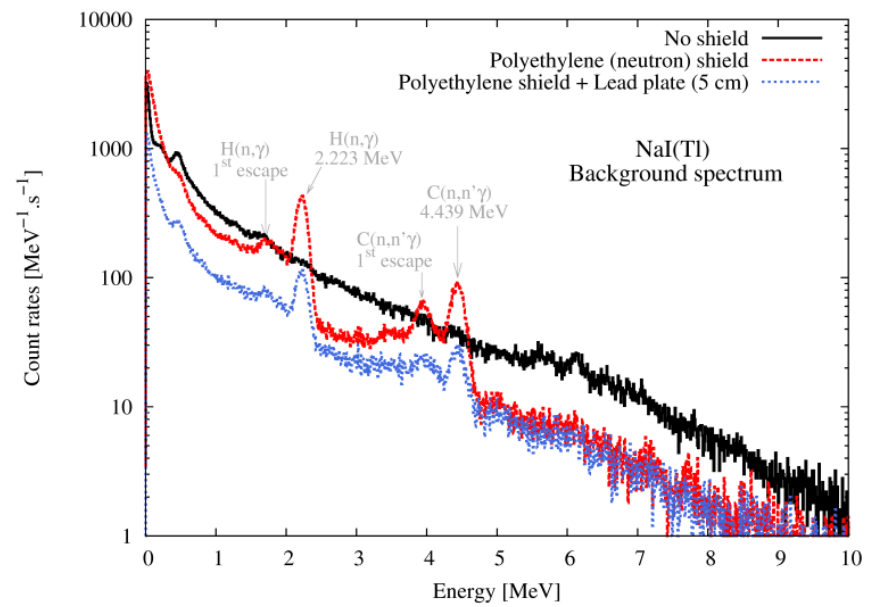

Fig. 5: Background gamma ray spectrum simulated with the MCNP6 pulse height tally on a NaI detector.

Expected count rates of gamma detectors are essential information to properly design the data acquisition system. This development is performed by CAEN in the framework of C-BORD.

As pulse height (F8) tallies are not reliable for neutron transport with MCNP [10], energy spectra were simulated using the F4 flux estimator over a cell, convolved with photoelectric, pair production and Compton scattering reaction cross-sections (FM card) [11].

Count rates are calculated by integrating the simulated spectra over the desired energy range, and then summing all detector contributions. Results without low-energy threshold are presented in Table II, showing that the final configuration reduces the gamma detector background of about a factor 4.5 for $\mathrm{NaI}$ detectors, but only 2.5 for $\mathrm{LaBr}_{3}$ detectors. This difference is likely caused by the $\mathrm{LaBr}_{3}$ detectors being closer to the tagged neutron beam than the $\mathrm{NaI}$ detectors and, therefore, less well shielded.

TABLE II. COUNT RATE $\left(\mathrm{S}^{-1}\right)$ ESTIMATIONS FOR SEVERAL SHIELD CONFIGURATIONS AND A $10^{8} \mathrm{~N} / \mathrm{S}$ GENERATOR EMISSION AND NO ENERGY THRESHOLD.

\begin{tabular}{lcc}
$\begin{array}{l}\text { Shield } \\
\text { configurations }\end{array}$ & $\begin{array}{c}20 \mathrm{NaI} \\
\text { detectors }\end{array}$ & $\begin{array}{c}4 \mathrm{LaBr}_{3} \\
\text { detectors }\end{array}$ \\
\hline No shield & $1.27 \mathrm{E} 7$ & $1.06 \mathrm{E} 5$ \\
Polyethylene & $9.38 \mathrm{E} 6$ & $2.28 \mathrm{E} 5$ \\
Polyethylene+ lead & $2.82 \mathrm{E} 6$ & $4.28 \mathrm{E} 4$ \\
\hline
\end{tabular}

As the number of events is very high at low energy, the influence of the low-energy threshold on the gamma count rate is studied in Table III.

TABLE III. COUNT RATE $\left(\mathrm{S}^{-1}\right)$ ESTIMATIONS AS A FUNCTION OF LOW-ENERGY THRESHOLD, ASSUMING A $10^{8} \mathrm{~N} / \mathrm{S}$ GENERATOR EMISSION AND A GAMMA DETECTOR SHIELD MADE OF A 5 CM THICK SMALL LEAD PLATE CLOSE TO THE DETECTORS.

\begin{tabular}{lcc}
$\begin{array}{l}\text { Low-energy } \\
\text { threshold }\end{array}$ & $\begin{array}{c}20 \mathrm{NaI} \\
\text { detectors }\end{array}$ & $\begin{array}{c}4 \mathrm{LaBr}_{3} \\
\text { detectors }\end{array}$ \\
\hline No threshold & $2.82 \mathrm{E} 6$ & $4.28 \mathrm{E} 4$ \\
$100 \mathrm{keV}$ & $1.58 \mathrm{E} 6$ & $2.51 \mathrm{E} 4$ \\
$300 \mathrm{keV}$ & $9.78 \mathrm{E} 5$ & $1.57 \mathrm{E} 4$ \\
$600 \mathrm{keV}$ & $6.69 \mathrm{E} 5$ & $1.13 \mathrm{E} 4$ \\
\hline
\end{tabular}

For the C-BORD project, it is planned to use the NaI detectors with a $600 \mathrm{keV}$ threshold, whereas the threshold on the $\mathrm{LaBr}_{3}$ detectors will be set to $100 \mathrm{keV}$, to allow the detection of chemical warfare agents. Thus, the total count rate of the whole $\mathrm{NaI}$ and $\mathrm{LaBr}_{3}$ detectors, which will be handled by the data acquisition system, would amount to about $7 \times 10^{5} \mathrm{~s}^{-1}$. For the individual detectors, the order of magnitude is $3 \times$ $10^{4} \mathrm{~s}^{-1}$ per NaI detector and $6 \times 10^{3} \mathrm{~s}^{-1}$ per $\mathrm{LaBr}_{3}$ detector.

However, these values do not account for the presence of interrogated cargo materials that will generate additional signal. To this end, a large item covering the beam path was added in the cargo container, close to the wall through which the neutron beam enters the container, to estimate the maximum expected count rate. As iron has a high neutron scattering cross-section, it was chosen to estimate a worst case scenario. This leads to a total count rate of $1 \times 10^{4} \mathrm{~s}^{-1}$ on the four $\mathrm{LaBr}_{3}$ detectors, and $4 \times 10^{4} \mathrm{~s}^{-1}$ on the twenty $\mathrm{NaI}$ detectors, with a total count rate of about $9 \times 10^{5} \mathrm{~s}^{-1}$.

\section{CONCLUSION AND PROSPECTS}

A compact and Rapidly Relocatable (about 48 hours) Tagged Neutron Inspection System (RRTNIS) has been designed, especially by optimizing neutron and gamma shields to ensure maximum protection of operators and to limit the detector background, while keeping the mechanical constraints reasonable. Count rate estimations have also been performed in order to design the digital data acquisition system. 
Following steps include simulations of time-of-flight and gamma-ray spectra of RRTNIS inspections for a series of test case scenarios. In parallel, laboratory measurements will be performed in order to construct the experimental elementary gamma signature database, necessary to unfold the spectra of the inspected compound materials.

\section{REFERENCES}

[1] G. Perret et al., "EURITRACK tagged neutron inspection system design" Journal of Physics: Conference Series, vol. 41, pp. 375-383, 2006.

[2] B. Pérot et al., "Development of the EURITRACK tagged neutron inspection system", NIM B, vol. 261, pp. 295-298, 2007.

[3] B. Pérot et al., "Materials Characterisation with the Associated Particle Technique", IEEE Nuclear Science Symposium and Medical Imaging Conference Record (NSS/MIC), n27-7, pp. 1702-1711, 2012.

[4] W. El Kanawati et al., "Conversion factors from counts to chemical ratios for the EURITRACK tagged neutron inspection system", NIM A, vol. 654, pp. 621-629, 2011.

[5] ICRP, Conversion Coefficients for use in Radiological Protection against External Radiation, ICRP Publication 74.Ann. ICRP 26(3-4), 1996.

[6] Professional plastics, Low Density Polyethylene [Online]: http://www.professionalplastics.com/LDPEPOLYETHYLENE

[7] Professional plastics, Borated Polyethylene [Online]: http://www.professionalplastics.com/BORATEDPOLYETHYLENE

[8] S. Bernard et al., "Development of the EURITRACK Tagged Neutron Inspection System: from simulation to experiment", in Proceedings of NEMEA-3, 3rd Workshop on Neutron Measurements, Evaluations and Applications, Borovets (Bulgaria), 25-28 October 2006.

[9] C. Eleon et al. " MCNP simulations for the neutron sensor design and gamma detector selection", Deliverable D3.1 \& D3.2 of the UNCOSS project, 2009.

[10] Los Alamos National Laboratory, "Monte Carlo N-Particle transport code", https://mcnp.lanl.gov/, 2016.

[11] A. Donzella et al., "Irradiation of container cargoes with neutron inpsection devices", Deliverable 5.3 of the ERITR@C European project, 2010. 